http://dx.doi.org/10.11646/zootaxa.3957.4.7

http://zoobank.org/urn:lsid:zoobank.org:pub:F404921C-1728-4354-9945-8DE12905DD31

\title{
The identity of Tachina westermanni Wiedemann, 1819 (Diptera: Calliphoridae or Tachinidae) with a solution to a nomenclatural problem
}

\author{
KNUT ROGNES ${ }^{1}$, JAMES E. O'HARA ${ }^{2} \&$ PIERFILIPPO CERRETTI ${ }^{3,4}$ \\ ${ }^{1}$ University of Stavanger, Faculty of Arts and Education, Department of Early Childhood Education, NO-4036 Stavanger, Norway. \\ E-mail:knut@rognes.no \\ ${ }^{2}$ Canadian National Collection of Insects, Agriculture and Agri-Food Canada, 960 Carling Avenue, Ottawa, Ontario, Canada, K1A \\ 0C6.E-mail: james.ohara@agr.gc.ca \\ ${ }^{3}$ DAFNAE-Entomology, University of Padova, Viale dell'Università 16, 35020 Legnaro (Padova), Italy \\ ${ }^{4}$ Department of Biology and Biotechnology 'Charles Darwin', 'Sapienza' University of Rome, Viale dell'Università 32, I-00185 Roma, \\ Italy.E-mail: pierfilippo.cerretti@uniromal.it
}

\begin{abstract}
Tachina westermanni Wiedemann, 1819 was based on four syntypes, two conspecific calliphorids and two conspecific tachinids. Two existing but contradictory lectotype fixations have resulted in confusion as to the correct application of the specific name westermanni Wiedemann. Evidence is presented showing that the lectotype fixation of Townsend in 1931 is valid and assigns westermanni Wiedemann to the Calliphoridae, with Pericallimyia westermanni as the valid binomen. The valid name for the tachinid taxon becomes Brachelia westermanni Robineau-Desvoidy, 1830 and a neotype is designated for it in the interests of nomenclatural stability.
\end{abstract}

Key words: Diptera, Calliphoridae, Tachinidae, zoological nomenclature, lectotype fixation, neotype designation, museum specimens, Afrotropical Region

\section{Introduction}

In the Catalogue of the Diptera of the Afrotropical Region (Crosskey 1980a) there are two taxonomic species based on the same nominal species, Tachina westermanni Wiedemann, 1819 from South Africa. The first is listed by Pont (1980: 795) in the Calliphoridae as Pericallimyia westermanni (Wiedemann) and the second is listed by Crosskey (1980b: 846) in the Tachinidae as Brachelia westermanni (Wiedemann).

Tachina westermanni was described by Wiedemann (1819: 23) on the basis of an unstated number of males (“స. Prom. bon. sp. [Promontorium Bonae Spei = Cape of Good Hope] Januario"). Subsequently it was included in the second part of his Aussereuropäische zweiflügelige Insekten (Wiedemann 1830: 291). Again, he gave no indication of the number of specimens he had before him, but this time stated that the material he examined was "In Westermann's und meiner Sammlung.". As will be explained below, Wiedemann had at least four specimens before him, thus all syntypes.

Zimsen (1954: 21) reported the existence of three specimens of Tachina westermanni in Westermann's collection in ZMUC. In a footnote to the entry that is marked with an asterisk on p. 21, Zimsen (1954: 8) noted that one of the specimens was in a separate case from the two others.

The fourth known syntype was discovered by Brauer and Bergenstamm (1893: 96 [184], as "Tachina Westermanni Wd (II. 291)") in von Winthem's collection ("C. Wth.") in NMW. It was reported to be identical with "Pseudolöwia sycophanta Schin.", also in NMW. This specimen originally formed part of Wiedemann's own collection (hence the expression "In [...] meiner Sammlung" in Wiedemann 1830), which subsequently was bought by von Winthem. Von Winthem's collection was purchased by NMW in 1852 (O'Hara 2013) and his specimens are recognizable today by the printed "Coll. Winthem" label (Pont 1995).

It has been known for a long time that the syntypic series of $T$. westermanni is mixed and consists of two 
different species. The material in Copenhagen consists of two conspecific calliphorid specimens and one tachinid specimen, whereas the material in Vienna consists of a single tachinid specimen, conspecific with the one in ZMUC. Two authors, Townsend (1931b) and Emden (1960), have designated lectotypes, explicitly or implicitly, for T. westermanni, with the result that the name applies to either the calliphorid or tachinid species depending on which lectotype designation is accepted as valid. This has led to the current situation in which the name is treated as valid for both species, in different families, a fact that went unnoticed for 35 years.

The purpose of the present paper is to discuss the merits of the actions of Townsend (1931b) and Emden (1960) and argue that Townsend proposed the valid designation. In addition, we propose a neotype for the nominal taxon Brachelia westermanni Robineau-Desvoidy (not Wiedemann) to preserve the name Brachelia westermanni for the tachinid taxon involved and ensure nomenclatural stability.

\section{Material and methods}

Acronyms of specimen depositories. BMNH—Natural History Museum, London, United Kingdom; CNCCanadian National Collection of Insects, Ottawa, Canada; MZUR-Museo di Zoologia, Università degli Studi di Roma "La Sapienza", Rome, Italy; NMW-Naturhistorisches Museum Wien, Vienna, Austria; OUMNH—Oxford University Museum of Natural History, Oxford, United Kingdom; ZMUC—Natural History Museum of Denmark, Zoological Museum, Copenhagen, Denmark.

Material. One of us (KR) examined the three syntypes in ZMUC. The syntype in Vienna was examined by JEOH during a visit to NMW in 2012 (O'Hara 2013) and by all of us from photographs of the specimen and its labels taken by JEOH. JEOH also photographed the holotype of Loewia sycophanta Schiner (NMW). A male of Pericallimyia westermanni (Wiedemann) recently captured by PC in South Africa (MZUR) was studied by KR.

Format for citing labels. Specimen labels are numbered successively from the highest to the lowest on the pin, the numbers being enclosed within parentheses. The lines on each label are separated by a slash (/). If the label text itself contains a printed or a handwritten slash, then all the label lines are separated by double slashes (//). The label text is usually cited without use of quotation marks. For one specimen the labels are distributed on three pins. Our comments are given in square brackets. For some labels both comments and label translation are given in square brackets, in such cases we have indicated explicitly what is a translation and what are our comments.

Photographic methods. The techniques used for preparation of Figs. 1-6, 9-11 were explained in Rognes (2012, 2013). The images in Figs. 12-19 were taken with a Sony NEX-C3 digital camera equipped with a 30mm macro lens and arranged into plates using Adobe Photoshop CS5. The method used by ZMUC for making the photographs used in Figs. 7 and 8 is not known.

\section{Wiedemann's description of Tachina westermanni}

Wiedemann (1819) described 44 new species, all based on specimens collected by Westermann, one of them being "34. Tachina Westermanni mihi" on p. 23. Wiedemann began with a summary of his description, stating that the species was a black Tachina ("T. anthracina") with the tip of the abdomen reddish ("ano ferrugineo."). Length in lines ["Longit. lin."] 61/2 " '. Prom. bon. sp. [= Cape of Good Hope] Januario". Then followed this description (our translation, with the German key expressions in double quotes, in parentheses; text in square brackets is added by us as explanation):

Antenna black, first flagellomere ("Endglied") not longer than, and also only slightly broader than the pedicel ("zweite" [segment of black antenna]). Palpus reddish yellow ("rostgelb") with a few setae at tip. Lower facial margin and gena ("Untergesicht und Backen") black with silvery microtrichosity shifting with direction of light ("schillernd"); frontal vitta ("Stirnmitte") black. Mesonotum ("Rückenschild") bluish-black ("bläulichschwarz"), anteriorly with white microtrichosity shifting with direction of light ("schillernd"); in this white area [are] two posteriorly diverging ("etwas auseinanderleufende") and broadening ("dicker werdende") black lines, in addition to one outer, hardly noticeable line on each side. Pleura ("Brustseiten") and abdomen ("Hinterleib") likewise bluish-black ("bläulichschwarz"), latter also with shifting white microtrichosity depending on direction of view ("letzerer in gewisser Richtung auch weiss schimmernd"). Tip of fifth abdominal segment ("Spitze des vierten Abschnitts") reddish brown ("rostbraun"). Wing slightly greyish. Wing veins blackish brown. Haltere ("Schwinger") brownish. Legs black. 
Wiedemann (1830: 291) mostly repeated his 1819 description but used the word coal-black ("kohlschwarz") when describing the mesonotum and the pleura, and wrote that the frons ("Stirn") was black, not using the term "Stirnmitte" employed in 1819. On p. 280 he stated that "... [e]s bleibt daher kein beständigeres Merkmal für die Gattung Tachina, als die stets nackte Fühlerborste [there does not exist a more reliable characteristic for the genus Tachina than the bare arista]", implying that a bare arista also characterizes his Tachina westermanni. He also added that the species was "Vom Kap [from Cape]" and was present in Westermann's and his own collection ("In Westermann's und meiner Sammlung"). This mention of his own collection was not given in the 1819 paper. Wiedemann's own collection was subsequently acquired by NMW (Pont 1995).

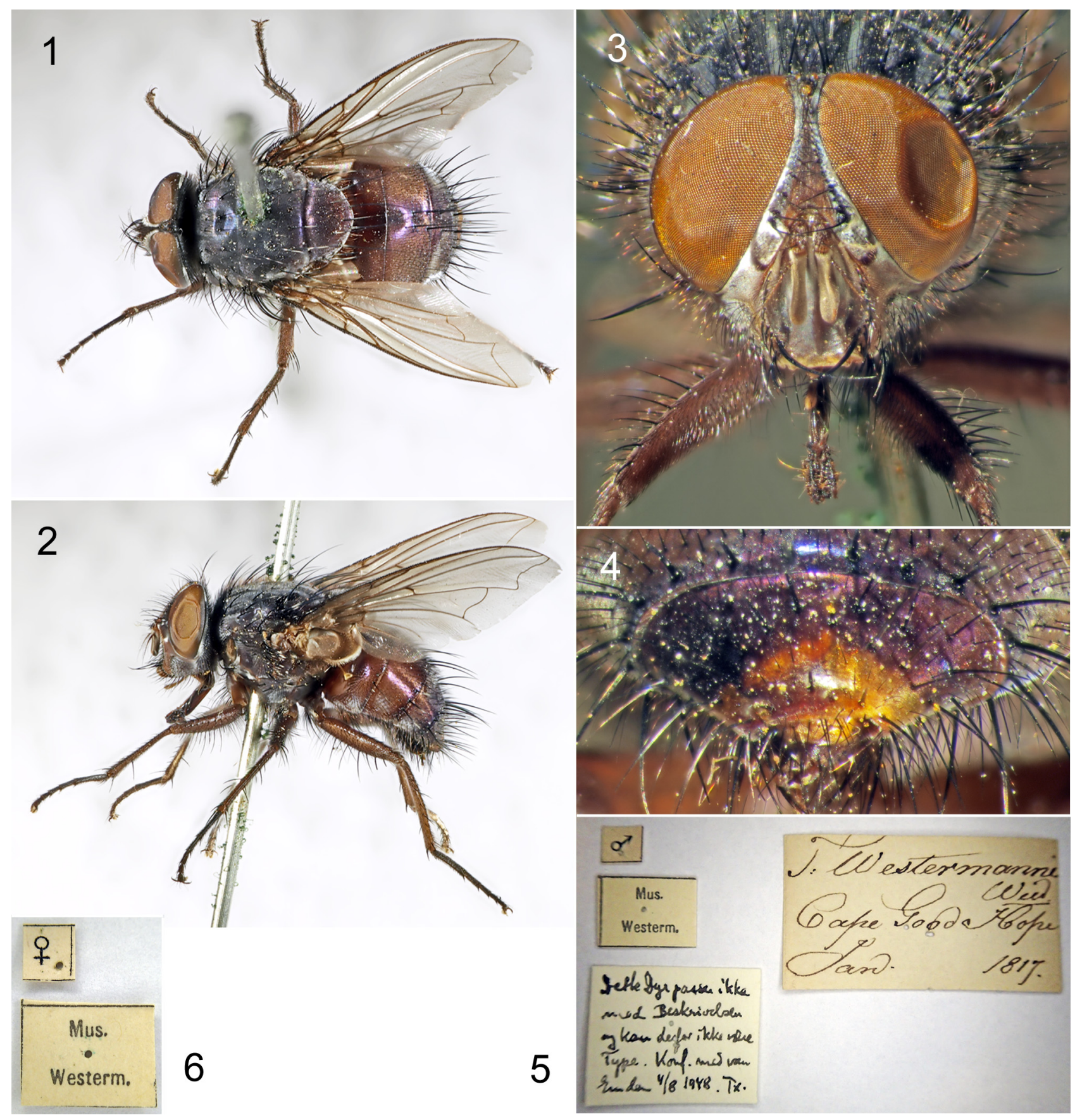

FIGURES 1-6. 1-5. Lectotype male of Tachina westermanni Wiedemann, 1819 (in ZMUC). 6. Paralectotype male of Tachina westermanni Wiedemann, 1819 (ZMUC). 1. Habitus, dorsal view. 2. Habitus, lateral view. 3. Head, from front. 4. Abdominal tergite 5, posterodorsal view. 5. Labels. 6. Labels. 


\section{Labels on the syntypes and condition of the specimens}

All the specimens considered as syntypes are males.

Syntype 1 (Calliphoridae, ZMUC, Figs. 1-5). Labels: (1) $\lesssim$ [printed on small square label]; (2) Mus. / Westerm. [printed] [= Museo Westermanni = Westermann's collection, according to Pont (1995: 147)]; (3) Dette dyr passer ikke // med Beskrivelsen // og kan derfor ikke være // Type. Konf. med van // Emden 4/8 1948. Tx. [our translation from Danish: "This specimen does not fit the description and therefore cannot be type. Conf. with van Emden 4/8 1948. Tx."] [handwritten label by S.L. Tuxen, curator in ZMUC at the time]; (4) T: Westermanni / Wied. / Cape Good Hope / Jan. 1817. [handwritten in Westermann's hand]. Condition: the specimen is in excellent condition, but the abdomen has a purplish hue (due to its age, almost 200 years) not found in the recent specimen in MZUR. The pin is long and slender.

Syntype 2 (Calliphoridae, ZMUC, Fig. 6). Labels: (1) $q$ [printed on small square label]; (2) Mus. / Westerm. [printed]. Condition: the specimen is in excellent condition but lacks the left mid tibia and tarsus, and the abdomen has a purplish hue as noted for syntype 1. It lacks a determination label but the big Westermann label under syntype 1 (Fig. 5) is clearly meant also for syntype 2 . The pin is similar to the one on syntype 1 .

Syntype 3 (Tachinidae, ZMUC, Figs 7-11). Labels: (1) TYPE [printed on red label] [on the same pin as specimen]; (2) zmuc / 00025017 [printed]; (3) Dette dyr passer // med Beskrivelsen // og må derfor være // Type. Konf. med van // Emden 4/8 1948. Tx. [our translation from Danish: "This specimen fits the description and therefore must be type. Conf. with van Emden 4/8 1948. Tx."] [handwritten by Tuxen]; (4) Westermanii [sic] / Wied. / Cap bon Sp. / Westermann [handwritten in Wiedemann's hand] [labels 2-4 on a separate pin beside specimen, there being no space for more labels on the pin carrying the specimen]. Condition: this syntype is not in the same good condition as the other Westermann specimens. The integument of the scutum is partly destroyed as shown in the ZMUC photograph (Fig. 7). The pin is very short and with a peculiar pin head (Fig. 7), suggesting it might have been collected on another occasion than syntypes 1 and 2 . The head of the syntype was glued to a card beside the specimen when received by KR, whereas it was attached to the body in the photographs from ZMUC (Figs. 7, 8). A leg fell off during shipping to KR.

Syntype 4 (Tachinidae, NMW, Figs. 12-15). Labels: (1) [small red square label]; (2) Westermani [sic] / 134 / Coll. Winthem [handwritten, except last line which is printed]; (3) Tachina / Westermanni Wied [handwritten, writer unknown]; (4) Westermanni / Wied / Cap [handwritten, possibly by Wiedemann himself]; (5) Type [printed on red label]. Condition: to judge from the photographs, the condition of the syntype is fair but the first flagellomeres are missing (Fig. 14).

\section{The syntypic status of the four specimens}

It is our contention that the aforementioned four specimens were seen by Wiedemann when he described Tachina westermanni and therefore have the status of syntypes. This is in agreement with the interpretations of Zimsen (1954), who examined the three specimens in ZMUC, and Emden (1960), who examined all four specimens. Below we discuss this matter in some detail.

Syntype 1 carries a big label including the text "[...] Jan. 1817.”. This label very likely also applies to syntype 2, both also carrying a similar "Mus. / Westerm." label. Neither syntypes 3 or 4 have a date on their labels. It follows that Wiedemann saw the two calliphorid syntypes when he wrote his description, which included the date "Januario".

Syntype 3, which is the specimen Zimsen (1954: 8) stated was kept in another case than the two others, carries a determination label written by Wiedemann himself (Fig. 11), so he presumably had this specimen before him. Syntype 4, even though bearing only one label possibly written by Wiedemann (Fig. 15, fourth from top), was once part of his own collection and hence was likely seen by him as well. Syntype 3 was accepted as a syntype by Zimsen (1954), who evaluated it within the context of a broader study of the insect types of Wiedemann in ZMUC. Both syntypes 3 and 4 were accepted as syntypes by Emden (1960), who carefully considered their status during his study of the identity of Tachina westermanni.

In light of the conclusions of these earlier assessments, and in the absence of evidence to the contrary, we accept both tachinid specimens as syntypes. 

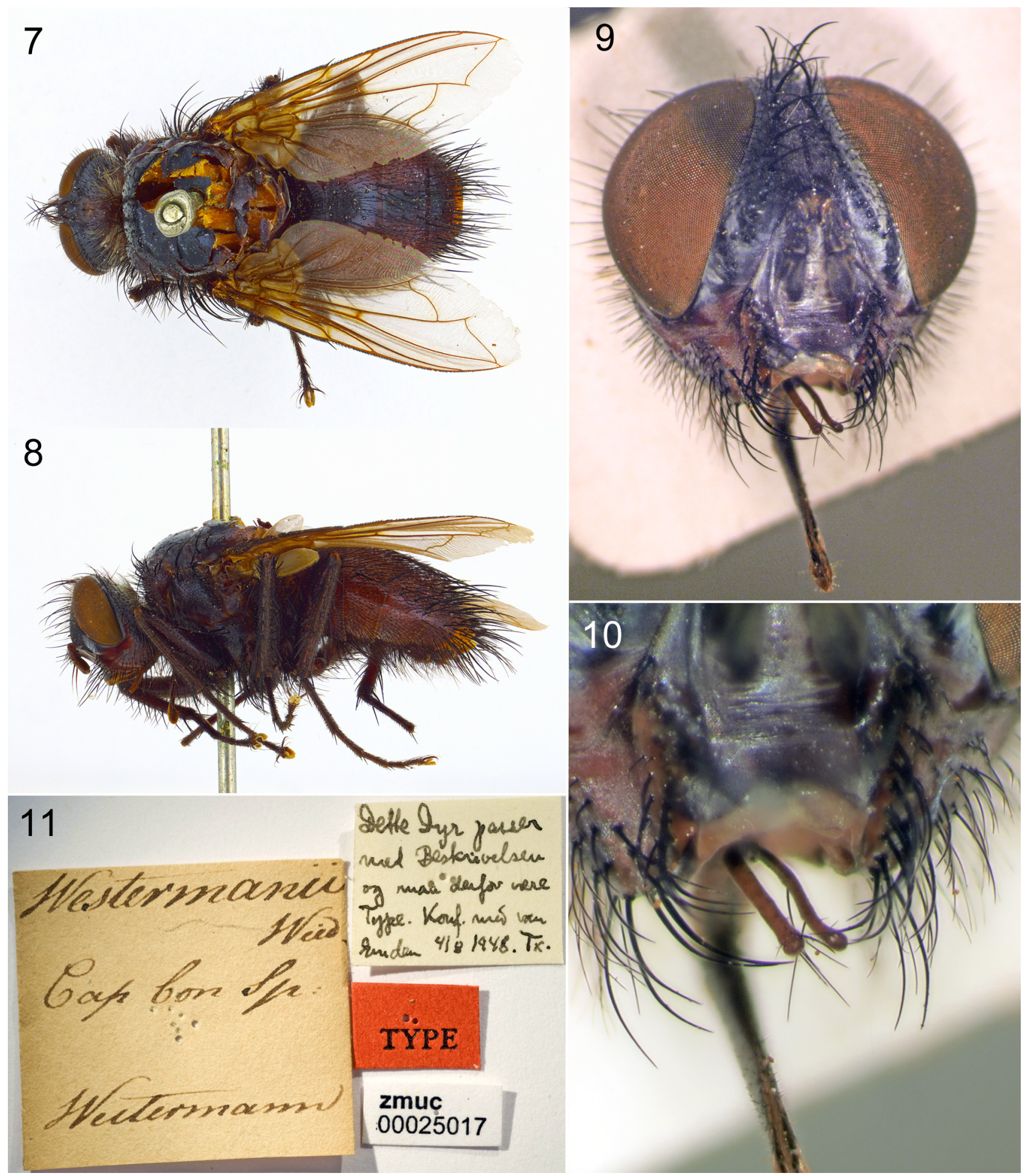

FIGURES 7-11. Neotype male of Brachelia westermanni Robineau-Desvoidy, 1830 (in ZMUC) (at the same time paralectotype male of Tachina westermanni Wiedemann, 1819). 7. Habitus, dorsal view. 8. Habitus, lateral view. 9. Head, from front. 10. Detail of palpi. 11. Labels. [Figures 7, 8 and 11 included by Courtesy of Natural History Museum of Denmark. These images can also be seen at http://daim.snm.ku.dk/digitaliseret-typesamling-detaljer-enkel-visning?catno=zmuc00025017]

All the syntypes are dark bluish, with a thin layer of white microtrichosity shifting with angle of view, and with a red-tipped abdomen (Figs. 4, 8, 13). Thus, all four syntypes satisfy this part of the original description. The abdomen of the first calliphorid syntype is now rather purplish on the sides, as shown in Fig. 2 (possibly due to its age). On the other hand, other parts of the description such as the reddish palpus, the bare arista, and the first flagellomere not being longer than the pedicel, only apply to syntypes 3 and 4, as noted by Emden (1960). The 
palpus of the calliphorid syntypes is currently somewhat reddish (after almost 200 years), but in the recent specimen in MZUR the palpus is very dark with at most the extreme tip slightly lightened. In syntypes 1 and 2 the first flagellomere is about $3 x$ the length of the pedicel and the arista is long plumose (Fig. 3). Emden (1960) also suggested that Wiedemann's description "Stirnmitte schwarz" (1819) and "Stirn schwarz" (1830) meant that the frons was of considerable width, which he considered not to be the case for the calliphorid syntypes. It is correct that in the calliphorid syntypes the eyes are more closely approximated than in the tachinid syntypes (compare Figs. 3 and 9), but even though the frontal vitta of the old calliphorid syntypes is now rather dark brown (Fig. 3), there is a black frontal vitta in the recent specimen examined. We assume it was black in the calliphorid syntypes at Wiedemann's time, and that Wiedemann's words regarding the frons colour were applicable also to the calliphorid syntypes.

\section{Townsend's treatment of Tachina westermanni Wiedemann, 1819}

Townsend spent six months in 1928 visiting European and American museums for the purpose of studying original type specimens of "oestromuscoid" flies (Townsend 1931a: 157). The results of the visits were presented in two "notes", the first embracing the New World types (Townsend 1931a), the second the Old World types (1931b, 1932). From his visit to Copenhagen he reported on Tachina westermanni Wiedemann as follows (Townsend 1931b: 375):

Tachina westermanni, Wied.-Male Ht and male Pt (wrongly det. female) in Copenhagen Westermann Coll., labelled “Cape Good Hope : Jan. 1817," are new genus published elsewhere. The infrascutellum is recessive.

This statement, without any doubt, refers to the two specimens listed above as syntypes 1 and 2 and housed in the Westermann collection. Not only does Townsend cite the original label on syntype 1 correctly (including the date) (Fig. 5), but he also notes that the "male Pt" is wrongly identified as a female. This latter statement refers, also without any doubt, to syntype 2, which carries a label with a printed "o" (Fig. 6).

The simple fact that the two calliphorid males are distinguished by different sex labels and that Townsend (1931b) identified the "male Pt" as the one with a female label is enough in our view to fix the other specimen, Townsend's "Male Ht" (which even carries the label text cited by Townsend), as a lectotype. This specimen is readily identifiable as Townsend's "Male Ht" (the lectotype) even though it does not carry any labels by Townsend to this effect. Townsend's action is a lectotype fixation, i.e., an implicit lectotypification, according to the terminology of O'Hara et al. (2009: 10).

For lectotypes designated before 2000, the Code Article 74.5 (ICZN 1999) states:

\footnotetext{
In a lectotype designation made before 2000, either the term "lectotype", or an exact translation or equivalent expression (e.g. "the type"), must have been used or the author must have unambiguously selected a particular syntype to act as the unique name-bearing type of the taxon. When the original work reveals that the taxon had been based on more than one specimen, a subsequent use of the term "holotype" does not constitute a valid lectotype designation unless the author, when wrongly using that term, explicitly indicated that he or she was selecting from the type series that particular specimen to serve as the name-bearing type.
}

It is our opinion that Townsend (1931b: 375) "unambiguously selected a particular syntype to act as the unique name-bearing type of the taxon" in question, i.e., Tachina westermanni Wiedemann, 1819.

The statement "new genus published elsewhere" by Townsend (1931b: 375) refers to the nominal genus Africomusca published by Townsend (1933: 441). He gives a detailed description of Africomusca including "no facial carina; $[. .$.$] facialia strongly ciliate over halfway; [\ldots]$ arista long-plumose; $[\ldots]$ eyes bare and nearly contiguous in male; $[\ldots] 5 \mathrm{R}\left[\mathrm{R}_{5}\right]$ open; $[\ldots]$ squamæ pilose above; $[\ldots]$ abdomen metallic violet-blue with yellow apex; [...] 1 MD [pair of medial discal setae] on intermediate segments [i.e., T3 and T4]. Africomusca is now considered a junior synonym of the calliphorid genus Pericallimyia Villeneuve (Pont 1980). The type species of Africomusca ("Genotype" in Townsend's phraseology) is cited as "Tachina westermanni Wied - Cape Good Hope", and the types of this species are cited as the "Male holotype and paratype, Copenhagen (Westermann Coll.) [...]", the very specimens listed by Townsend (1931b: 375) from Westermann's collection in ZMUC. Townsend (1933: 441) further noted: "T. westermanni RD nec [not] Wied was evidently a very distinct form". 
Zimsen (1954: 8) emphasized that Townsend saw only these two calliphorid syntypes and did not see syntype 3 in ZMUC (a tachinid). This does not affect Townsend's fixation of a calliphorid syntype as lectotype because the Code requires only that the lectotype be an original syntype (cf. Article 74.5's mention of "syntype" and "the type series"); there is no provision that the designator must have seen all existing syntypes.

We thus consider syntype 1 in ZMUC as the lectotype of Tachina westermanni Wiedemann, 1819 and treat this name as valid in the combination Pericallimyia westermanni (Wiedemann, 1819), as used by Zumpt (1956: 83), Pont (1980: 795) and Sabrosky (1999: 126).

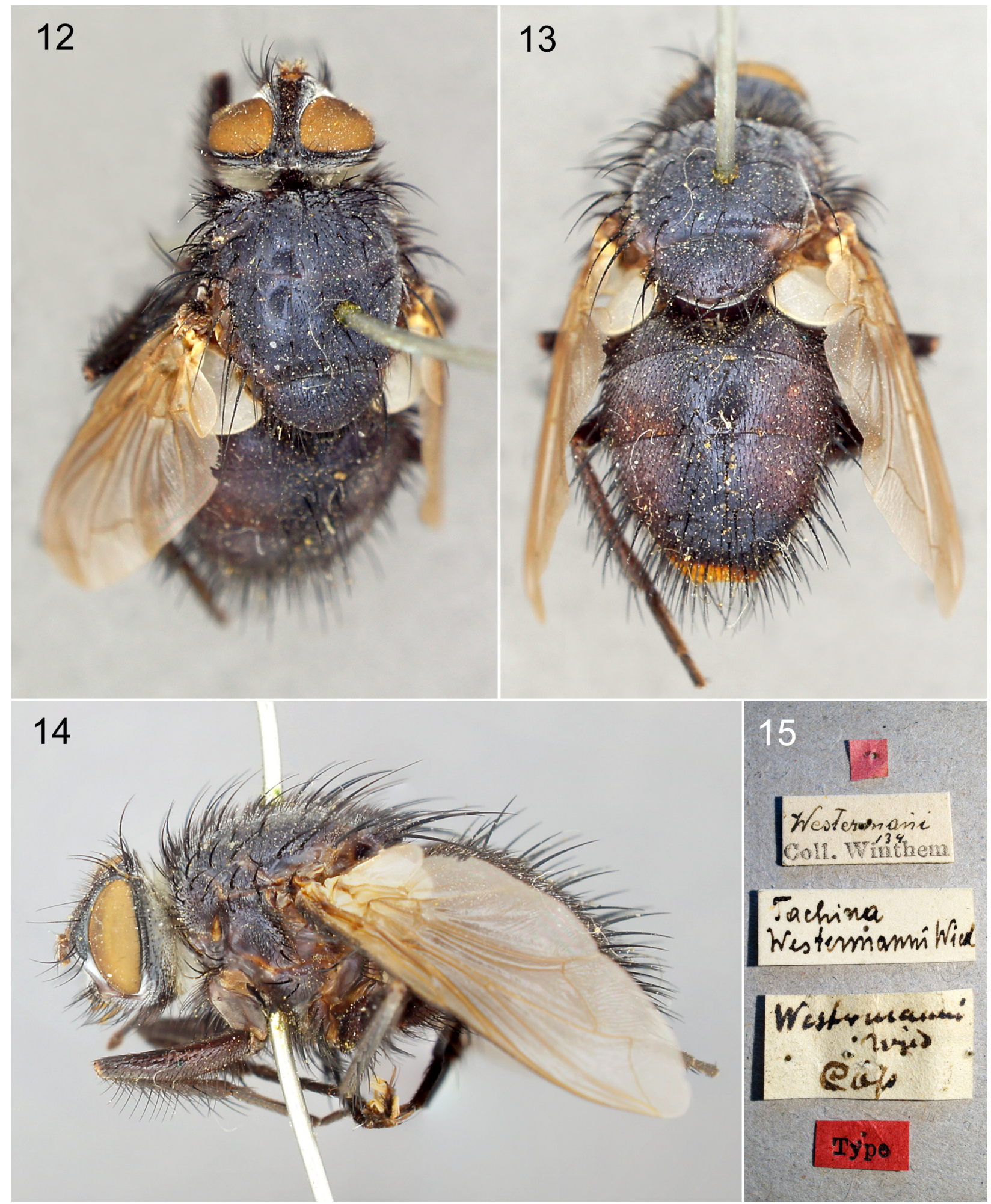

FIGURES 12-15. Paralectotype male of Tachina westermanni Wiedemann, 1819 (in NMW). 12. Habitus, dorsal view. 13. Habitus, posterodorsal view. 14. Habitus, lateral view. 15. Labels. 
The "Male Ht and male Pt" seen by Townsend (1931b) have been given (by KR) red labels as lectotype and paralectotype, respectively. Syntype 3 has also been given (by KR) a red paralectotype label. The fourth syntype (in NMW) (also a tachinid) has not been given such a label by us.

\section{Emden's treatment of Tachina westermanni Wiedemann, 1819}

Emden (1960) accepted the aforementioned four specimens in ZMUC and NMW as syntypes of Tachina westermanni Wiedemann, 1819. He did not, however, accept Townsend's lectotype fixation and proceeded to formally designate the tachinid syntype in ZMUC (syntype 3 above) as lectotype. Emden was influenced in part by the synonymization of Tachina westermanni Wiedemann, 1819 and Pseudoloewia sycophanta (Schiner, 1868) by Brauer \& Bergenstamm (1893: 96 [184]). Brauer \& Bergenstamm wrote:

Pseudolöwia sycophanta Schin. (Loewia) Novara Reise ist identisch mit Tachina Westermanni Wd. (II. 291) C. Wth. Die Art muss daher Brachelia Westermanni Wd. heissen ... Robineau Desv. beschreibt 1830 die T. Westermanni Wd. (nach einer Type) als Gattung Brachelia. p. 61.

This entry requires some explanation. Loewia sycophanta (Figs. 16-19) was described in great detail by Schiner (1868: 323) in the Diptera part of the expedition report of the frigate Novara. It was subsequently transferred to the new genus Pseudoloewia Brauer \& Bergenstamm (1889: 136 [68]). The expression "Wd. (II. 291)" refers to Wiedemann (1830: 291). The expression "C. Wth." refers to the collection of von Winthem, including Wiedemann's own collection that was acquired by NMW before Brauer \& Bergenstamm's time. The specimen referred to by the expression "nach einer Type" is the lost holotype of Brachelia westermanni Robineau-Desvoidy, 1830: 62, but the genus Brachelia itself was described on p. 61, hence the page number "p. 61". Brauer \& Bergenstamm here refer to syntype 4 of Tachina westermanni Wiedemann, a tachinid.

To Emden (1960: 403) it was "perfectly obvious" that most parts of Wiedemann's descriptions in 1819 and 1830 were not based on "the species to which Townsend assigned the name westermanni Wied."; i.e., the calliphorid Pericallimya westermanni (Townsend). Making a tabular comparison between Wiedemann's and Townsend's descriptions, he concluded that Wiedemann's description best fitted the tachinid syntype in ZMUC (syntype 3), which was correctly interpreted as conspecific with syntype 4 in NMW and the holotype of Pseudoloewia sycophanta, also in NMW.

Emden (1960) went on to designate the tachinid specimen in ZMUC (Figs. 7-11), "which is labelled in Wiedemann's handwriting 'Westermanni Wied Cap. bon. sp. Westermann' [not entirely correctly cited, cf. Fig. 11] as the type of Brachelia westermanni in agreement with Robineau-Desvoidy's and Brauer and Bergenstamm's identifications". Emden here explicitly designated syntype 3 as lectotype of Tachina westermanni Wiedemann.

Emden discussed but did not recognize Townsend's implicit lectotype fixation for two reasons. First, he objected that "in this paper Townsend [1931b] only lists a 'male Ht and male Pt' as present in the Westermann Collection, without stating in this paper (or any other paper belonging to that series) that he proposes to designate types" [italics in the original] (Emden 1960: 404). This objection is not valid. Numerous implicit lectotypifications of this sort have been accepted (e.g., Crosskey 1969: 88, O'Hara et al. 2009: 10) and they are valid, provided the author gave additional information, besides the mere mention of "holotype", that makes it possible to identify the intended specimen in collections without any doubt.

Emden's second objection follows directly after his first: "Nor could a wholesale selection of types without comparison with the descriptions be acceptable and valid.". This objection is allied to the criticism made earlier in the paper, to the effect that Townsend, "in the face of the important discrepancies between Wiedemann's descriptions and the specimens seen by himself [...] was not justified in declaring one of them to be the holotype in contradiction to the typical specimen in the Wiedemann-Einthem [sic] collection on which Brauer and Bergenstamm based their statements". This objection is also not valid. Designating a lectotype is a nomenclatural and not a taxonomic act. The Code requires that the lectotype must be an original syntype, but there is no provision that it must be the specimen that most closely matches the description. In this case Wiedemann's descriptions undoubtedly match Townsend's lectotype in some, but not all, respects.

We therefore reject Emden's objections to Townsend's lectotype fixation and consider it as valid. This has the consequence of invalidating Emden's own, and subsequent, lectotype designation. Consequently, the use by Crosskey (1980b: 846) of Wiedemann's name westermanni in the combination Brachelia westermanni for the 
tachinid which has Loewia sycophanta Schiner as a synonym is therefore also not valid. This means that the tachinid "Brachelia westermanni" of Crosskey (1980b) needs a valid name.

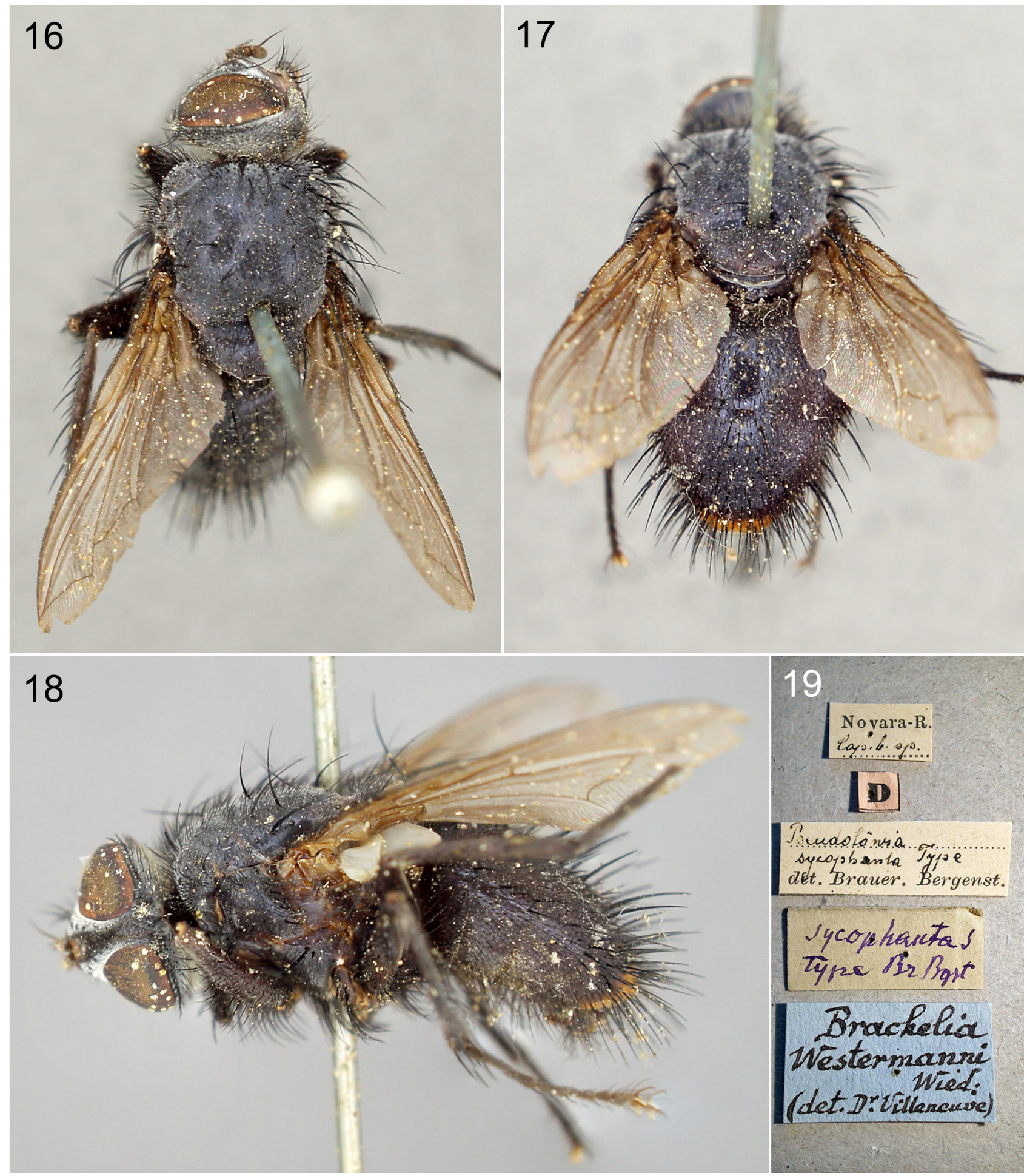

FIGURES 16-19. Holotype of Loewia sycophanta Schiner, 1868 (in NMW). 16. Habitus, dorsal view. 17. Habitus, posterodorsal view. 18. Habitus, lateral view. 19. Labels.

\section{Brachelia westermanni Robineau-Desvoidy, 1830}

Loewia sycophanta Schiner is a junior synonym of Tachina westermanni Wiedemann sensu Crosskey (1980b). It was used as a valid name in the combination Brachelia sycophanta (Schiner) by Townsend (1932: 42; 1937: 134; 
1939: 223). It is, however, a junior subjective synonym of Brachelia westermanni Robineau-Desvoidy, 1830: 62, and employing this latter name as the valid one for this species will preserve nomenclatural stability.

The genus Brachelia Robineau-Desvoidy, 1830: 61 was described both in French and Latin as follows (citing here only the French text):

Antennes ne descendant pas jusqu'au péristome; les deux derniers articles égaux en longueur: le troisième cylindrique, non plus épais que le deuxième. Premiers articles du chète très-courts. Péristome assez allongé, à épistome saillant; faciaux ciligères le long du péristome; corps cylindriforme, à teintes cérulées assez brillantes.

[The antennae do not reach the lower facial margin; the two last segments equal in length: the third cylindrical, not thicker than the second. First segments of arista very short. Oral margin quite long, lower facial margin projecting; oral margin with setae; body cylindrical, with bluish quite shining colour.]

This is a tachinid, not a calliphorid, genus. The type species by monotypy, "BRACHELIA WESTERMANNI. R.D." (Robineau-Desvoidy 1830: 62), was described both in French and Latin as follows (citing only the French text):

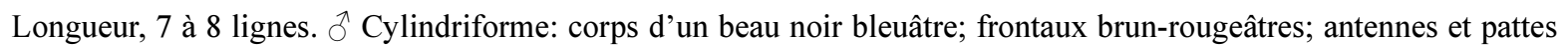
noires; côtés du front et face bruns; anus rouge.

[Length, 7 to 8 lines. $\widehat{C}$ Cylindrical: body handsomely bluish black; frontal plates reddish brown; antennae and legs black; sides of frons and face brown; tip of abdomen red.]

Note the description of the abdominal tip ("anus") as red. Robineau-Desvoidy saw only a single specimen of his new nominal species: "Le seul individu que je connaisse provient du cap de Bonne-Espérance, et fait partie de la collection de M. Dejean. M. Latreille l'avait étiqueté Tachina Westermanni".

The Diptera part of Dejean's collection went to Bigot, and "what remains is in OUMNH" (Evenhuis et al. 2010: 238). According to Pont (personal communication to KR) the Tachinidae part of the Dejean collection was given to BMNH. The holotype of $B$. westermanni has not been found in OUMNH (Pont, personal communication to $\mathrm{KR}$ ) or in BMNH (Wyatt, personal communication to KR) and is assumed lost. But it is fairly certain, at least not unreasonable to assume, that the holotype of this nominal species belonged to the same taxon as the two tachinid syntypes of Tachina westermanni Wiedemann and the holotype of Loewia sycophanta Schiner (as treated by Crosskey 1980b: 846).

When Tachina westermanni Wiedemann was (erroneously) considered a tachinid taxon belonging in the genus Brachelia Robineau-Desvoidy, the name Brachelia westermanni Robineau-Desvoidy became a junior secondary homonym and junior subjective synonym of Tachina westermanni Wiedemann. Now that Wiedemann's name Tachina westermanni applies to a calliphorid species, Brachelia westermanni Robineau-Desvoidy becomes the valid name for the tachinid species. The only necessary action is to fix the identity of this name by designating a neotype to replace the lost holotype. In our view, the best specimen to select as neotype is the specimen in ZMUC that Emden (1960: 404) invalidly designated as lectotype for Tachina westermanni Wiedemann. This will preserve the use of the name Brachelia westermanni for the tachinid, even though the specific epithet is now attributed to Robineau-Desvoidy and not Wiedemann.

We hereby designate as neotype for Brachelia westermanni Robineau-Desvoidy a male in ZMUC (Westermann's collection) (Figs. 7-11), with these labels: (1) TYPE [printed on red label] [on the same pin as specimen]; (2) zmuc / 00025017 [printed]; (3) Dette dyr passer // med Beskrivelsen // og må derfor være // Type. Konf. med van // Emden 4/8 1948. Tx. [our translation from Danish: "This specimen fits the description and therefore must be type. Conf. with van Emden 4/8 1948. Tx."] [handwritten by Tuxen]; (4) Westermanii [sic] / Wied. / Cap bon Sp. / Westermann [handwritten in Wiedemann's hand] [labels 2-4 on a separate pin beside specimen, there being no space for more labels on the pin carrying the specimen]. One of us (KR) has added a red neotype label on a third pin beside the specimen. This pin thus carries two red labels: one as paralectotype for Tachina westermanni Wiedemann, and a second as neotype for Brachelia westermanni Robineau-Desvoidy. The neotype label is on top.

Type locality: "Cap bon Sp." [Cape of Good Hope], the same as the lost holotype. 


\section{Code compliance issues-ICZN Article 75. Neotypes}

The purpose of the present neotype designation is to clarify the taxonomic status of Brachelia westermanni Robineau-Desvoidy, 1830: 62, the holotype of which is lost. This clarification is necessary to preserve the use of the binomen Brachelia westermanni for the taxon involved (ICZN Article 75.3.1.).

The neotype is the same specimen (syntype 3, above) that was used by Emden (1960) in his invalid lectotype designation for Tachina westermanni Wiedemann, hence all the characters of this specimen are valid for the taxon denoted by the name Brachelia westermanni Robineau-Desvoidy (ICZN Article 75.3.2.).

The label data given above assures the recognition of the specimen designated (ICZN Article 75.3.5.).

The holotype of Brachelia westermanni Robineau-Desvoidy was from Dejean's collection, parts of which are in BMNH and OUMNH while the remainder is considered lost. Nigel P. Wyatt (BMNH) and Adrian C. Pont (OUMNH) have informed us that no specimen of Brachelia westermanni is present among Dejean's holdings in BMNH or OUMNH (ICZN Article 75.3.4.).

The neotype fits the original description of Brachelia westermanni Robineau-Desvoidy (ICZN Article 75.3.5.). The neotype originates from the same type locality as the lost holotype (ICZN Article 75.3.6.).

The neotype is the property of ZMUC (ICZN Article 75.3.7.).

\section{Nomenclatural summary_Pericallimyia westermanni}

Tachina westermanni Wiedemann, 1819: 23. Male lectotype in ZMUC, by fixation of Townsend 1931b: 375. Type locality: South Africa, Cape of Good Hope (published as "Prom. bon. sp.").-Wiedemann 1830: 291. Redescription.

Pericallimyia westermanni: Zumpt 1956: 83.-Pont 1980: 795.-Sabrosky 1999: 126 (“[...], T. westermanni Wiedemann 1819 from the Cape of Good Hope, now a good species of Pericallimyia in the Calliphoridae. [...]").

\section{Nomenclatural summary—Brachelia westermanni}

Brachelia westermanni Robineau-Desvoidy, 1830: 62. Male neotype, in ZMUC, here designated. Type locality: South Africa, Cape of Good Hope (published as "cap de Bonne-Espérance").

Loewia sycophanta Schiner, 1868: 323. Male holotype, by monotypy, in NMW. Type locality: South Africa, Cape of Good Hope (published as "Cap der guten Hoffnung").

Pseudoloewia sycophanta: Brauer \& Bergenstamm 1889: 136 [68] (published as "Pseudolöwia nob. sycophanta S. Cap b. sp.").

Brachelia westermanni: Brauer \& Bergenstamm 1893: 53 [141] (published as "Brachelia R.D. 1830. Westermanni Wd. [Pseudolöwia n. olim (29) sycophanta S.]" [text in square brackets part of quoted passage]). Misidentification [Calliphoridae].-Brauer \& Bergenstamm 1893: 96 [184] (published as "Brachelia R.D. Ad P. 1, p. 136.-Pseudolöwia sycophanta Schin. (Loewia) Novara Reise ist identisch mit Tachina Westermanni Wd.”). Misidentification [Calliphoridae].-Crosskey 1980b: 846. Misidentification [Calliphoridae].Evenhuis et al. 2010: 49. Misidentification [Calliphoridae]. In these four citations Tachina westermanni Wiedemann was used in the sense of the tachinid for which the valid name is here interpreted as Brachelia westermanni Robineau-Desvoidy.

Brachelia sycophanta: Townsend 1932: 42; 1937: 134; 1939: 223.

\section{Acknowledgements}

We would like to thank Thomas Pape (ZMUC) for making the syntypes of Tachina westermanni in ZMUC available for study by KR. He also generously granted permission to re-use the images of the neotype of Brachelia westermanni Robineau-Desvoidy and its labels published on the ZMUC website, and shared with KR his opinion 
on Townsend's lectotype designation. Many thanks also to Adrian C. Pont (OUMNH) for sharing with us his opinion of the handwriting of the labels on the NMW syntype of Tachina westermanni and for searching the OUMNH collections for the lost holotype of Brachelia westermanni Robineau-Desvoidy. Nigel P. Wyatt kindly searched the BMNH collection for the same lost holotype. Peter Sehnal (NMW) is thanked for his generous assistance during a visit by JEOH to NMW in 2012. Thomas Pape and two anonymous reviewers are thanked for their useful comments to the manuscript.

\section{References}

Brauer, F. \& Bergenstamm, J.E. von (1889) Die Zweiflügler des Kaiserlichen Museums zu Wien. IV. Vorarbeiten zu einer Monographie der Muscaria Schizometopa (exclusive Anthomyidae). Pars I. Denkschriften der Kaiserlichen Akademie der Wissenschaften. Wien. Mathematisch-Naturwissenschaftliche Classe, 56 (1), 69-180 + 11 pls.

[Note: Also published separately in Wien, 1890, 112 pp. +11 pls. Dating of these two editions of the same work follows Evenhuis (2014).]

Brauer, F. \& Bergenstamm, J.E. von (1893) Die Zweiflügler des Kaiserlichen Museums zu Wien. VI. Vorarbeiten zu einer Monographie der Muscaria Schizometopa (exclusive Anthomyidae). Pars III. F. Tempsky, Wien, 152 pp.

[Note: Also published in 1894, Denkschriften der Kaiserlichen Akademie der Wissenschaften. Wien. MathematischNaturwissenschaftliche Classe, 60 [1893], 89-240. Dating of these two editions of the same work follows Evenhuis (2014).]

Crosskey, R.W. (1969) The type-material of Indonesian Tachinidae (Diptera) in the Zoological Museum, Amsterdam. Beaufortia, 16, 87-107.

Crosskey, R.W. (Ed.) (1980a) Catalogue of the Diptera of the Afrotropical Region. British Museum (Natural History), London, $1437 \mathrm{pp}$.

Crosskey, R.W. (1980b) Family Tachinidae. In: Crosskey, R.W. (Ed.), Catalogue of the Diptera of the Afrotropical Region. British Museum (Natural History), London, pp. 822-882.

Emden, F.I. van (1960) Keys to the Ethiopian Tachinidae-III Macquartiinae. Proceedings of the zoological Society of London, $134,313-487$. http://dx.doi.org/10.1111/j.1469-7998.1960.tb05596.x

Evenhuis, N.L. (2014) Publication and dating of parts IV-VII of Brauer \& Bergenstamm's Die Zweiflügler des Kaiserlichen Museums zu Wien (1889-1894). Zootaxa, 3790 (3), 495-499. http://dx.doi.org/10.11646/zootaxa.3790.3.8

Evenhuis, N.L., O'Hara, J.E., Pape, T. \& Pont, A.C. (2010) Nomenclatural studies toward a world list of Diptera genus-group names. Part I: André-Jean-Baptiste Robineau-Desvoidy. Zootaxa, 2373, 1-265.

International Commission on Zoological Nomenclature (1999) International Code of Zoological Nomenclature. 4th Edition adopted by the International Union of Biological Sciences. International Trust for Zoological Nomenclature, London, xxix $+306 \mathrm{pp}$.

O'Hara, J.E. (2013) A visit to the Vienna Museum with a brief history of the tachinid collection. The Tachinid Times, 26, 3038. Available from: http://www.nadsdiptera.org/Tach/WorldTachs/TTimes/Tach26.html (accessed 23 January 2015)

O'Hara, J.E., Shima, H. \& Zhang, C.-T. (2009) Annotated catalogue of the Tachinidae (Insecta: Diptera) of China. Zootaxa, $2190,1-236$.

Pont, A.C. (1980) Family Calliphoridae. In: Crosskey, R.W. (Ed.), Catalogue of the Diptera of the Afrotropical Region. British Museum (Natural History), London, pp. 779-800.

Pont, A.C. (1995) The dipterist C.R.W. Wiedemann (1770-1840). His life, works and collections. Steenstrupia, 21, 125-154.

Robineau-Desvoidy, J.-B. (1830) Essai sur les myodaires. Mémoires présentés par divers savants à l'Académie Royale des Sciences de l'Institut de France, Sciences Mathémathiques et Physiques, Séries 2, 2, 1-813.

Rognes, K. (2012) Revision of the Afrotropical species of the Bengalia peuhi species-group, including a species reassigned to the B. spinifemorata species-group (Diptera, Calliphoridae), with notes on the identity of Ochromyia petersiana Loew, 1852 (Diptera, Rhiniidae). Zootaxa, 3553, 1-79.

Rognes, K. (2013) A new species in the genus Pseudorhyncomyia Peris, 1952 and the identity of $P$. deserticola Zumpt and Argo, 1978 (Diptera; Rhiniidae). Zootaxa, 3736, 249-264. http://dx.doi.org/10.11646/zootaxa.3736.3.3

Sabrosky, C.W. (1999) Family-group names in Diptera. An annotated catalog. Myia, 10, 1-360.

Schiner, J.R. (1868) Diptera. In: Reise der österreichischen Fregatte Novara um die Erde in den Jahren 1857, 1858, 1859 unter den Befehlen des Commodore B.von Wullerstorf-Urbair. Zoologischer Theil. Zweiter Band. 1. Abtheilung. B. K. Gerold's Sohn, Wien, vi +388 pp. +4 plates. Available from: http://www.biodiversitylibrary.org/item/32633\#page/422/mode/lup (accessed 23 April 2015)

Townsend, C.H.T. (1931a) Notes on American oestromuscoid types. Revista de Entomologia, 1, 65-104.

Townsend, C.H.T. (1931b) Notes on Old World œstromuscoid types.-Part I. Annals and Magazine of natural History, Series $10,8,369-391$. 
http://dx.doi.org/10.1080/00222933108673408

Townsend, C.H.T. (1932) Notes on Old World œstromuscoid types.-Part II. Annals and Magazine of natural History, Series $10,9,33-57$. http://dx.doi.org/10.1080/00222933208673463

Townsend, C.H.T. (1933) New genera and species of Old World oestromuscoid flies. Journal of the New York Entomological Society, 40, 439-479. [1932]

Townsend, C.H.T. (1937) Manual of myiology in twelve parts. Part V. Muscoid generic diagnoses and data. Glossinini to Agriini. Charles Townsend \& Filhos, Itaquaquecetuba, São Paulo, 232 pp.

Townsend, C.H.T. (1939) Manual of myiology in twelve parts. Part VIII. Oestroid generic diagnoses and data. Microtropesini to Voriini. Charles Townsend \& Filhos, Itaquaquecetuba, São Paulo. 405 pp. [an "Addenda and corrigenda" of two pages, numbered as pp. 407-408, was published later.]

Wiedemann, C.R.W. (1819) Beschreibung neuer Zweiflügler aus Ostindien und Afrika. Zoologisches Magazin, 1 (3), 1-39. Available from: http://www.biodiversitylibrary.org/item/51679\#page/5/mode/1up (accessed 12 February 2015)

Wiedemann, C.R.W. (1830) Aussereuropäische zweiflügelige Insekten. Als fortsetzung des Meigenschen Werkes. Vol. 2. Schulz, Hamm, xii +684 pp, 5 pls.

Zimsen, E. (1954) The insect types of C.R.W. Wiedemann in the Zoological Museum in Copenhagen. Spolia Zoologica Musei Hauniensis, 14, 1-43.

Zumpt, F. (1956) Calliphoridae (Diptera Cyclorrhapha) Part 1: Calliphorini and Chrysomyiini. Exploration du Parc National Albert Mission G. F. de Witte (1933-1935), 87, 1-200. 